\title{
Monitoring Aquatic Life by Checking Water Pollution
}

\author{
R. Sridevi ${ }^{1}$, Salma Begum ${ }^{2}$, T. Soumya ${ }^{3}$, J. Chaitanya ${ }^{4}$, Ch. Gayathri ${ }^{5}$ \\ ${ }^{1}$ Associate professor-Electronics and communication BVRIT Hyderabad College of Engineering for Women Bachupally, \\ Hyderabad, Telangana, India \\ 2,3,4,5 UG student -Electronics and communication BVRIT Hyderabad College of Engineering for Women Bachupally, \\ Hyderabad, Telangana, India
}

\begin{abstract}
Industries directly dump chemicals \& waste into the rivers and oceans. The price of which is paid by aquatic life and people living nearby. Each year the river water is getting more polluted. Now- a-days $\mathrm{pH}$ values of water resources used by most of the villagers is very close to one of the acids, which is harmful to their life. Many species of the oceans are getting extinct due to pollution. To take suitable action against this problem, we first need data to analyze what is happening inside the water. Major objects considered for analyzing the water quality here are pH, turbidity. The aim of this paper is to upload the data in the database such as location of the river, $\mathrm{pH}$, turbidity of the water. Based on the data in the database PH, Turbidity, Temperature, data, database, website necessary actions are to be taken.
\end{abstract}

Keywords- PH, Turbidity, Temperature, data, database, website, wixsite

\section{INTRODUCTION}

Over two thirds of Earth's surface is covered by water. As Earth's population continues to grow, people are putting everincreasing pressure on the planet's water resources. In a sense, our oceans, rivers, and other inland waters are being "squeezed" by human activities so their quality is reduced. Poorer water quality means water pollution. Water pollution can be defined in many ways. Usually, it means one or more substances have built up in water to such an extent that they cause problems for animals or people. Oceans, lakes, rivers, and other inland waters can naturally clean up a certain amount of pollution by dispersing it harmlessly. Water pollution is the leading worldwide cause of death and disease, e.g. due to water-borne diseases. The causes of water pollution include a wide range of chemicals and pathogens as well as physical parameters. Contaminants may include organic and inorganic substances. Elevated temperatures can also lead to polluted water. A common cause of thermal pollution is the use of water as a coolant by power plants and industrial manufacturers. Elevated water temperatures decrease oxygen levels, which can kill fish.

\section{II.HARDWARE DESCRIPTION}

The Components required to analyze the water quality are the $\mathrm{pH}$ sensor, Turbidity sensor, Arduino Uno.

\section{A. Arduino Uno}

The Arduino Uno [1] is an open-source microcontroller board based on the Microchip ATmega328P microcontroller and developed by Arduino.cc. The board is equipped with sets of digital and analog input/output pins that may be interfaced to various expansion boards and other circuits. The board has
14 digital I/O pins in which six can be used as PWM output, 6 analog I/O pins, and is programmable with the Arduino IDE (Integrated Development Environment), via a type B USB cable. It can be powered by the USB cable or by an external volt battery, though it accepts voltages between 7 and 20 volts. It is also similar to the Arduino Nano and Leonardo.

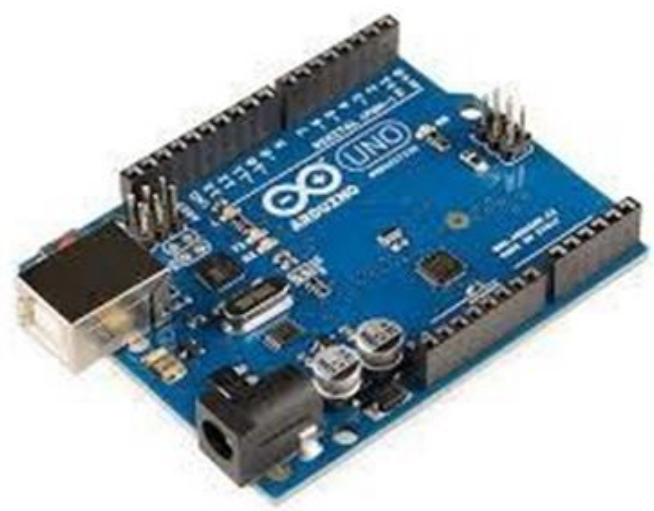

Fig. 1. Arduino Uno

B. pH Sensor

$\mathrm{pH}$ is the numeric representation of gram-equivalent per liter of hydrogen ion concentration in any solution. It varies between 0 to 14 . It is the logarithmic measurement of moles of hydrogen ions per liter of solution. The solutions having $\mathrm{pH}$ value between 0 to 7 are acidic solutions with large concentration of hydrogen ions whereas solutions having $\mathrm{pH}$ value between 8 to 14 are basic solutions with small hydrogen concentration. The solutions having $\mathrm{pH}$ value of 7 are neutral solutions. Measuring the $\mathrm{pH}$ gives the measure of alkalinity or acidity of a solution. $\mathrm{pH}$ meter [2] basically works on the fact that interface of two liquids produces an electric potential which can be measured. $\mathrm{pH}$ affects most chemical and biological processes in water. It is one of the most important environmental factors limiting species distributions in aquatic habitats. Different species flourish within different ranges of $\mathrm{pH}$, with the optima for most aquatic organisms falling between $\mathrm{pH}$ 6.5-8. U.S[3]. EPA water quality criteria for $\mathrm{pH}$ in freshwater suggest a range of 6.5 to 9 . Even small changes in $\mathrm{pH}$ can shift community composition in streams. This is because $\mathrm{pH}$ alters the chemical state of many pollutants (e.g., copper, ammonia), changing their solubility, transport and bioavailability. This can increase exposure to and toxicity of metals and nutrients to aquatic plants and animals. 


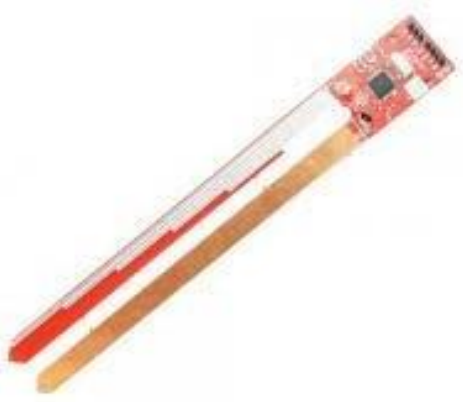

Fig. 2. $\mathrm{pH}$ sensor

\section{Turbidity Sensor}

Turbidity [4] is the cloudiness or haziness of a fluid caused by large numbers of individual particles that are generally invisible to the naked eye, similar to smoke in air. The measurement of turbidity is a key test of water quality. Fluids can contain suspended solid matter consisting of particles of many different sizes. While some suspended material will be large enough and heavy enough to settle rapidly to the bottom of the container if a liquid sample is left to stand (the settable solids), very small particles will settle only very slowly or not at all if the sample is regularly agitated or the particles are colloidal[5]. These small solid particles cause the liquid to appear turbid. Turbidity sensor is basically an optical sensor consisting of an IR Transmitter and receiver. It works on the principle of refraction of wavelength between photo transistor and diode. More details on working of Turbidity Sensor.

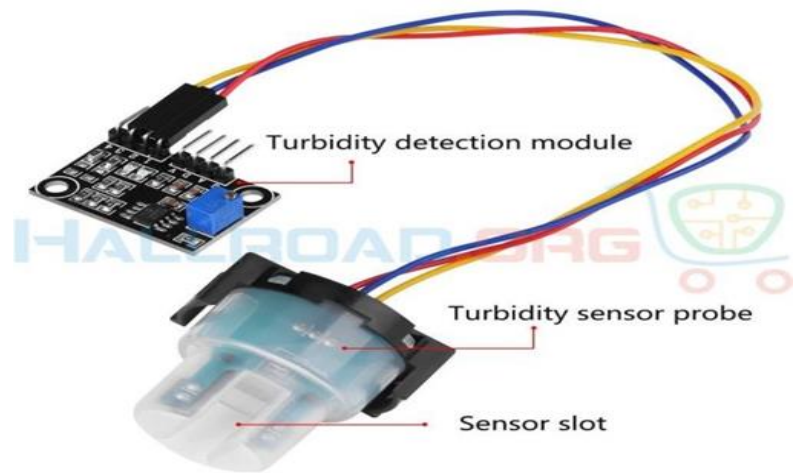

Fig. 3. Turbidity sensor

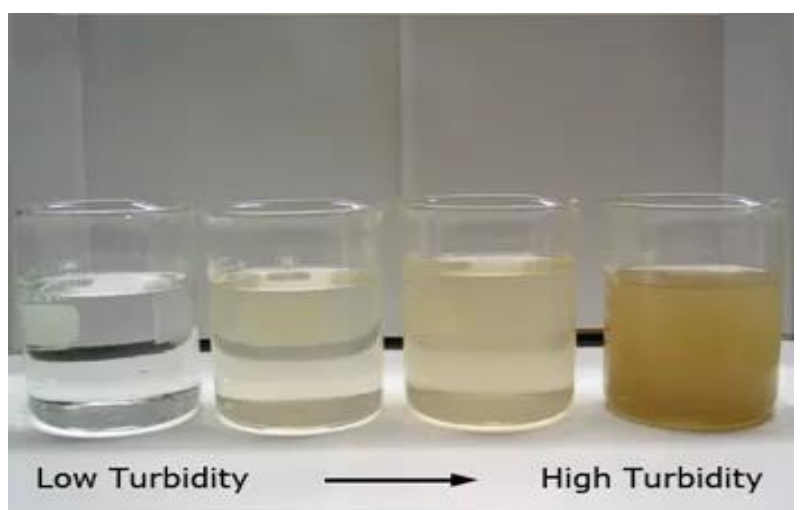

Fig. 4. Turbidity Water

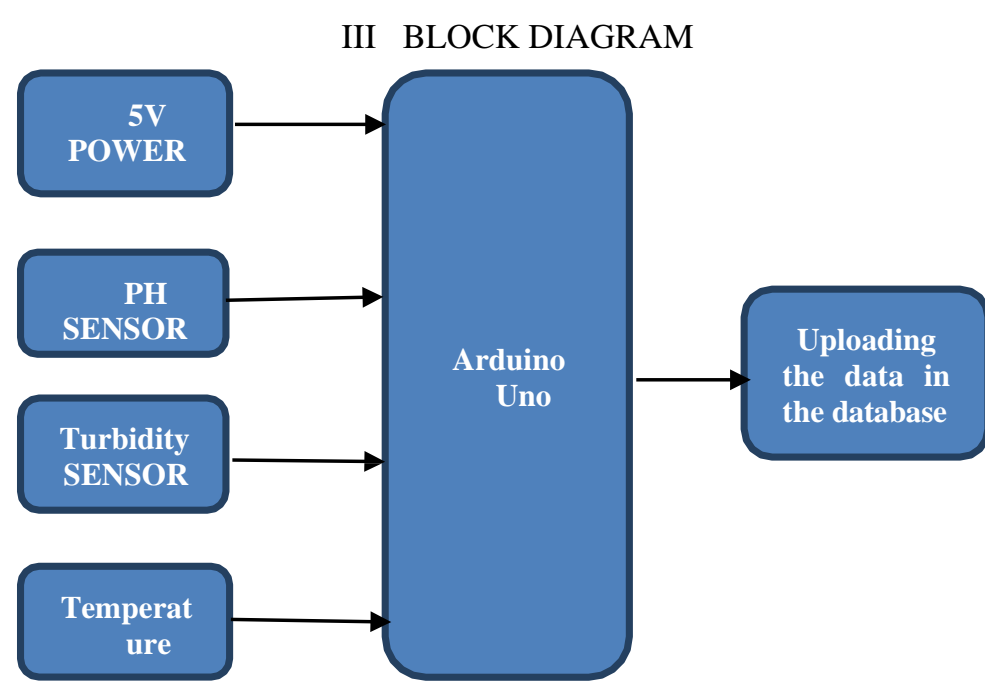

Fig. 5. Block Diagram

The $\mathrm{pH}$ sensor, Turbidity sensor, Temperature sensor need to be interfaced with the Arduino. Based on the code written in the Arduino IDE, the values will be displayed in the serial monitor.

\section{IV.SOFTWARE DESCRIPTION}

\section{A. Arduino IDE}

The Arduino Integrated Development Environment (IDE) is a cross-platform application (for Windows, macOS, Linux) that is written in functions from $\mathrm{C}$ and $\mathrm{C}++$. It is used to write and upload programs to Arduino compatible boards

\section{B. Wixsite}

For creating a website, we have used wix.com. The software Wix.com [6] is used to create HTML websites and mobile sites through the use of online drag and drop tools. For creating the template in wix.com first we need to link all the details and set the settings based on our requirements. we need to create a database, here we are creating two databases one for uploading the river water quality and other is comments database. wixsite also contains the home page code, where we need to write the code based on our wixsite requirements. Finally, we need to adjust all the contents, how it should look in mobile and in desktop.

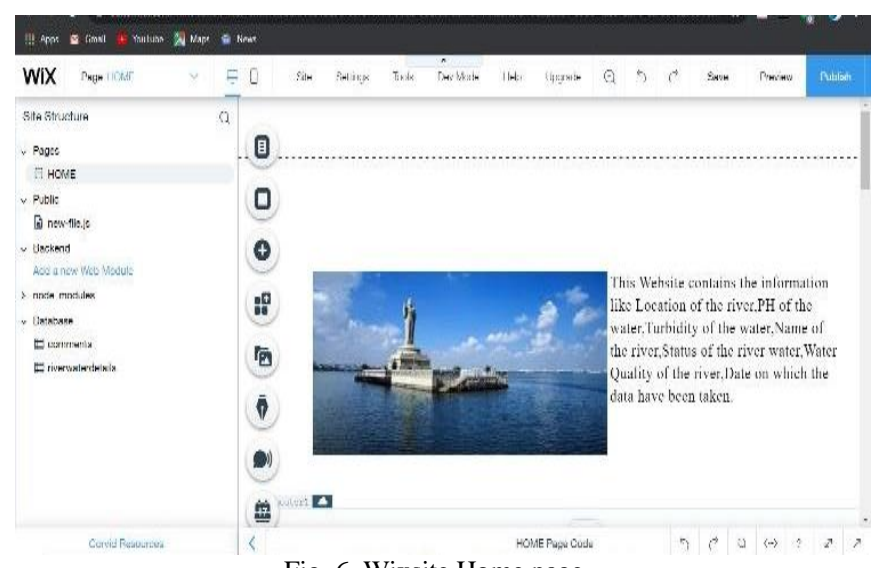

Fig. 6. Wixsite Home page 


\section{A. Code used for creating a website} figure

The code used for creating a website is shown in below

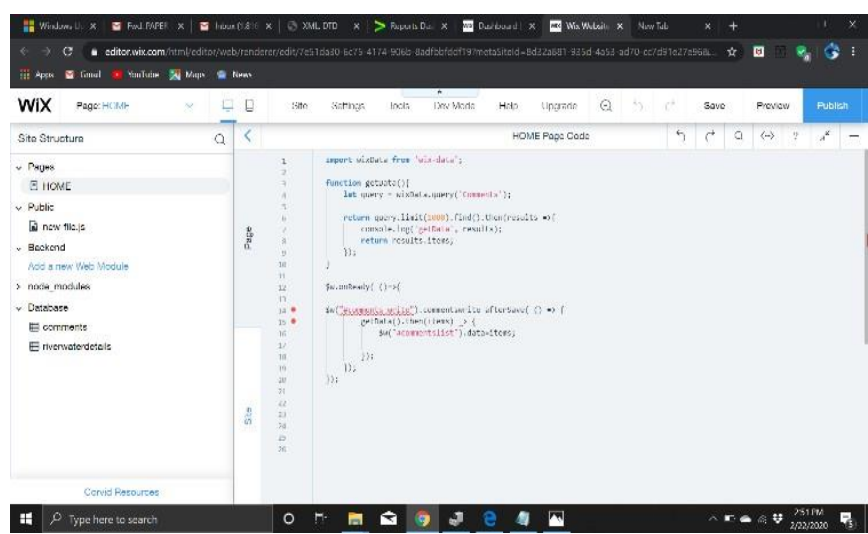

Fig. 7. Code used for creating a website

B. Tools required to edit the website

There are certain tools to be required to edit the website wix.com which is shown in below figure

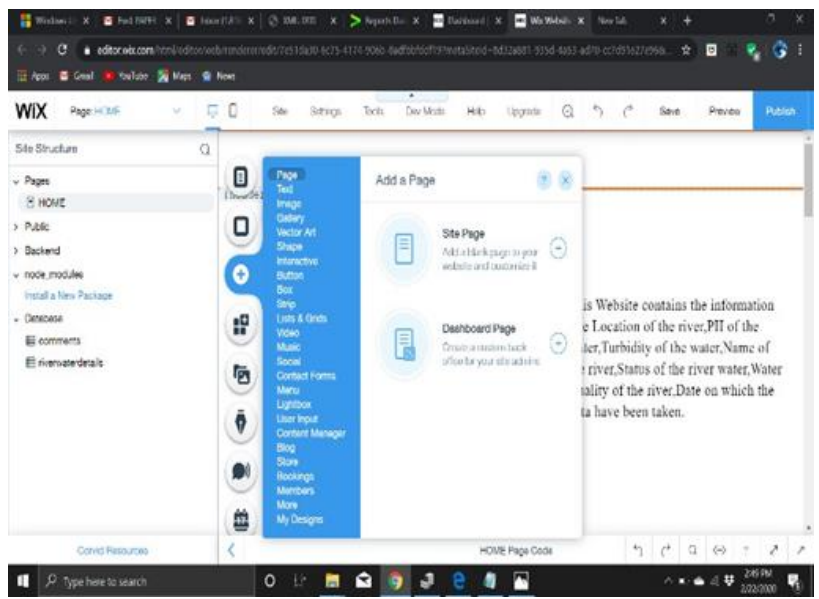

Fig. 8. Tools required to edit the website

C. Comment box in website is shown below

We can also create a comment box in the website which is shown in below figure.

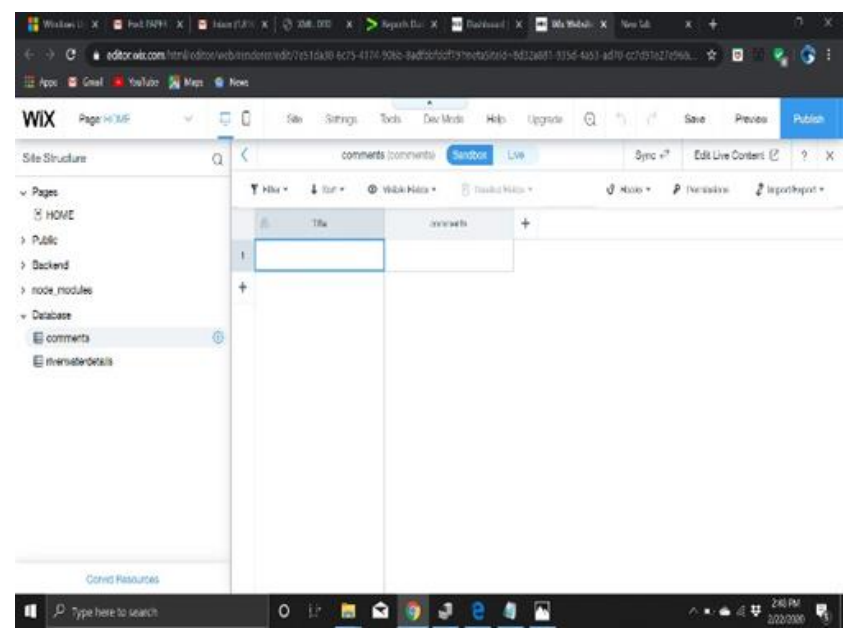

Fig. 9. Comments box database

\section{River quality database}

The below figure shows the data base of river quality collected from different places.

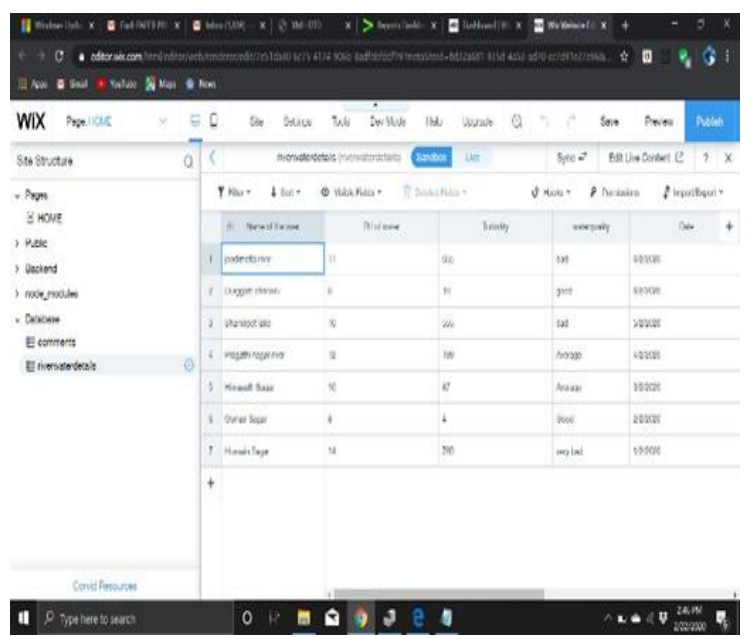

Fig. 10. River water quality database

\section{WORKING}

The $\mathrm{pH}$ sensor, Turbidity sensor, Temperature sensor are interfaced with the Arduino. Based on the code written in the Arduino IDE, the values will be displayed in the serial monitor. The data we get from the sensors such as $\mathrm{pH}$, turbidity and temperature of water will be uploaded manually in the river water quality database. All Based on the data in the database, suitable actions are taken by the government authorities.

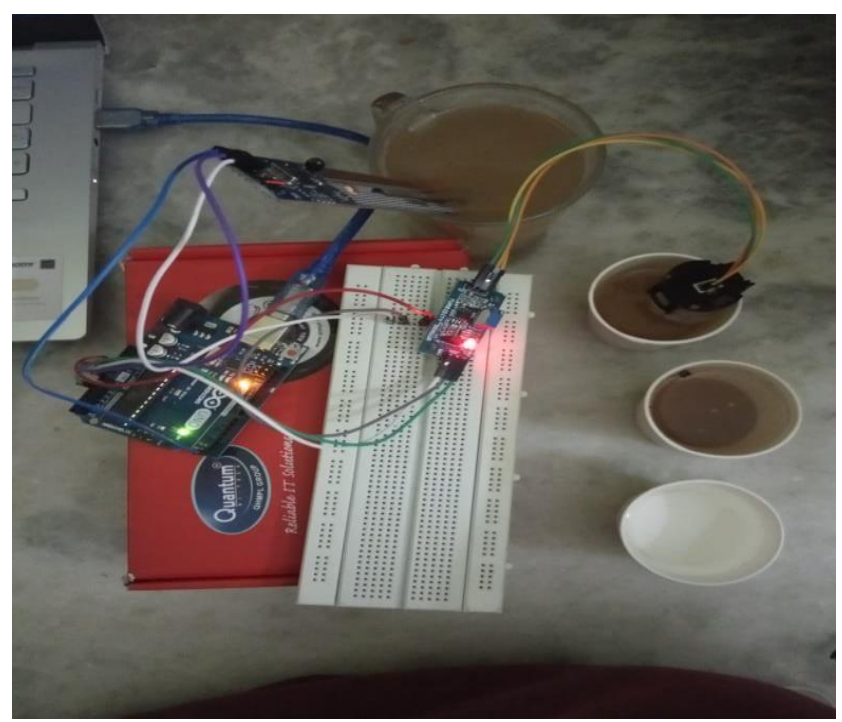

Fig.11. Hardware setup

\section{RESULT}

The result of this system will show the readings by each sensor which specifies the $\mathrm{pH}$ value, Turbidity and temperature of water. Each sensor shows the values corresponding to the presence of their parameters as the parameter increases, values get increased. We have set a predetermined threshold value for each Sensor. Then we will upload the values in the wix.com. 


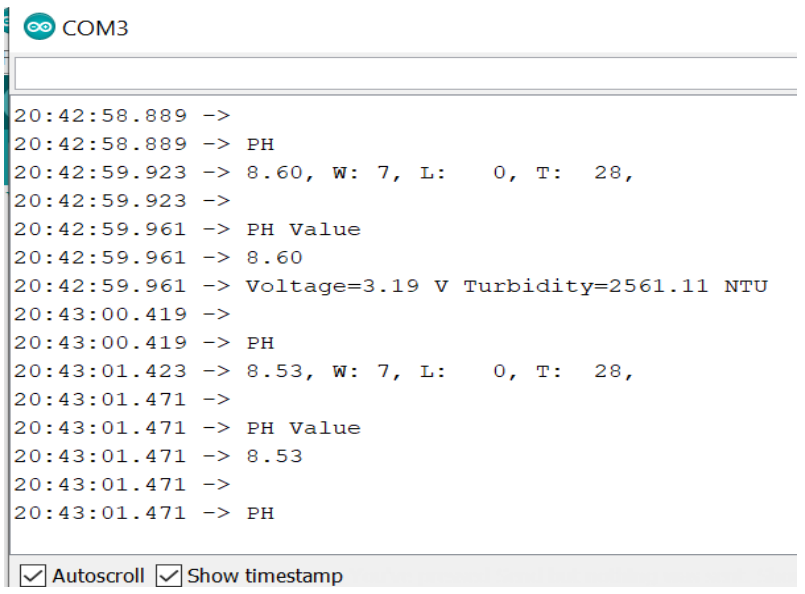

Fig 12. PH, Turbidity and Temperature values

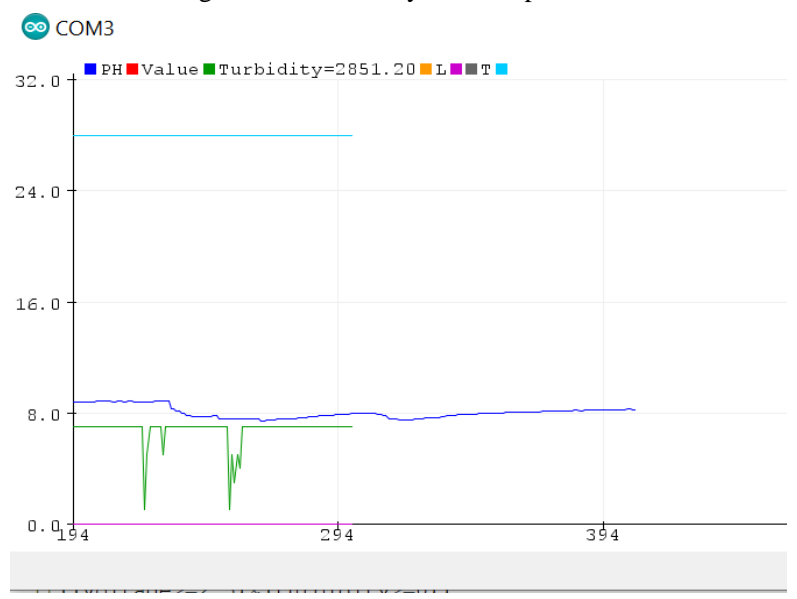

Fig 13. Graphical values of $\mathrm{pH}$, Turbidity, Temperature

\section{CONCLUSION}

This project proposes a system "MONITORING AQUATIC LIFE BY CHECKING WATER POLLUTION" which can be used to monitor the $\mathrm{pH}$ level, turbidity and temperature levels of water. It is a commercial device which can be used in small-scale industry. The sensors are interfaced to the Arduino which will process the inputs and update these values on the wix.com. We can share this data with industries who are responsible for it and they can take action to reduce pollution. Moreover, after certain measures we can also see if the aquatic life is populating or not and what are the factors which are responsible for their growth of population.

\section{FUTURE SCOPE}

Instead of using multiple sensors we are planning to implement this system using a single sensor which can detect all the specified parameters.

\section{REFERENCES}

[1] Prof. K.R.Katole, Vrushali Bagade, Bhagyashree Bangade and Ankita soni, "Hazardous Gas Detection using ARDUINO" IJSTE International Journal of Science Technology \& Engineering | Volume 2 | Issue 10 | April 2016

[2] Kakooei Saeid, Mokhtar Che Ismail, Bambang Ari-Wahjoedi, "An overview of $\mathrm{pH}$ sensors based on iridium oxide: fabrication and application", Int. J. Mater. Sci. Innovat, vol. 1, pp. 62-72, 2013.

[3] Himmel, D.; Goll, S. K.; Leito, I.; Krossing, I. (2010). "A Unified pH Scale for all Phases". Angew. Chem. Int. Ed. 49 (38): 6885-6888.

[4] C. D. Kelley et al., "An affordable open-source turbidimeter", Sensors (Basl)., vol. 14, no. 4, pp. 7142-7155, 2014

[5] Earth Systems, Clear Solutions newsletter - Focus on Turbidity 2003

[6] Wix launches a brand new HTML5 site builder as Flash heads the way of the dodo, Harrison Weber, The Next Web, 26 March 2012 